\title{
Study on Factors of University in Innovation Collaboration
}

\author{
Fan $\mathrm{Xia}^{1}, \mathrm{Li} \mathrm{Yi}{ }^{2}$, \\ ${ }^{1}$ South China University of Technology, Guangzhou, China Tel.: +86-20-87114109, fanxia321@163.com \\ ${ }^{2}$ South China University of Technology, Guangzhou, China, Tel.: 15017508087, nichiko@ foxmail.com
}

\begin{abstract}
:
Based on the contingency factors of the formation of organization relationship, this paper studies a wealth of literature at home and abroad and classifies the motives of university's collaboration with industry. From the organizational aspect, through meta-analysis, it studies systematically the factors that influence innovation collaboration and discusses the possible area of research in future. Furthermore, it explains how moderators affect innovation collaboration variables and relevant innovation pattern and policy design, which is a key to promote innovation collaboration theory for the next.
\end{abstract}

Keyword: innovation collaboration; university; motive; cooperation proneness; factor

\section{Introduction}

Innovation collaboration has benefited the university and college significantly in modern world. The most significant benefits by academic is complementing their own academic research by securing funds for graduate students and lab equipment, and by seeking insights into their own research ${ }^{[1]}$. At the same time, the changes in the characteristics of science and technology innovation activities make people pay more attention to the importance of innovation collaboration in colleges and universities, and further cause the new ideas of science and technology by scholars for the scientific research orientation and relevant policy making. In recent years, there is abundance of research achievements about the motive and proneness of innovation cooperation, as well as the corresponding channels of characteristics in university, knowledge transfer and its influence on the innovation performance. The literature laid the important theoretical basis to further clarify the dialectical relationship between the activities of science and technology, and clear the related function of interaction in innovation cooperation in basic and applied research in colleges and universities.

As to motivation of innovation cooperation of university, the literature was investigated from different perspectives including transaction cost, resource dependence theory, and strategic management and so on. However, there is a big difference in different organizations to participate in innovation cooperation, which may be on account of the heterogeneity in organizational level. The factors influencing the organizational heterogeneity display in different aspects including scale, academic ability, funding and group regulation, geographical position, etc. However, the existing literature has not come into a consistent conclusion. For example, Schartinger et al. (2002) indicates there is U-shape relationship between school scale and its collaboration tendency. However, D Este\&Fontana (2007), Giuliani (2010), and other scholars found no effect of the organization scale on innovation cooperation through the empirical study. In term of academic ability, Giuliani \&Arza (2009), Laursen et al. (2011), and other scholars believe that the academic ability has a positive influence on innovation cooperation. But, Ponomariov (2008), Perkmanna (2012) and other scholars have made opposite conclusion.

Based on comparison analysis on a large number of related literatures at home and abroad, the research analyzes the related literature about factors of innovation cooperation in colleges and university by meta-analysis, in order to provide enlightenment and reference in future research. Structure of this paper are arranged as follow: the introduction puts forward problems and introduce the related literature at home and abroad; The second part gives a brief description on Meta-analysis; The third part systematically studied the papers about innovation collaboration, and estimated results as well as moderating effect; The forth part is the limitation and conclusion. 


\section{Methodology and Data}

\subsection{Research Method}

This paper uses the meta-analytic procedure of Hunter and Schmidt (1990). As a quantitative research method, meta-analysis was used at beginning in clinical medical research, which was named in 1970 by Glass formally, as a comprehensive statistical analysis method of single studies ${ }^{[2]}$. Meta-analysis is to study based on previous research rather than repeat itself simply. It provides a more systematic and comprehensive research integration in a period of time for a certain topic, which can overcome some limitations that exist in an individual research, such as discipline limited and incomplete information, etc. To some extent, it also avoids the selective bias and model bias existing in the original literature. The characteristic of meta-analysis made it outstanding in literature review. In the past 20 years, there appeared abundance of empirical literature on innovation collaboration. However, some of conclusions were not the same or even conflicted with each other. Based on the procedure of related literature, correlations were corrected individually. In this paper, correlation coefficient was used as the main data. The main goals in this paper include: (1) to calculate and estimate the effect size and its significance of every variable; (2) to make a heterogeneity test on samples that come from different literature; (3) to make sure the moderators that influencing the heterogeneity among each variable.

\subsection{Data and Coding Procedure}

The data was collected with "university", "innovation collaboration/UIC", "enterprise", "factor", "motivation/orientation", “determinant" as keywords, mostly from two journals including (1) Research Policy, (2)Technovation, in addition, some other database including (1) Elsevier SDOL; (2) JSTOR in order to supplement the research samples, from January 1990 to January 2014. Finally it reaches a total of 133 search literature. Studies were included in the meta-analysis if they met the following criteria: (1) all literature must be empirical study of factors affecting university in innovation cooperation;(2) the dependent variable must be innovation cooperation proneness;(3) all literature must involve the correlation coefficient of cooperative proneness of university (e.g., $r$ values, standard error, $t$ value, regression coefficient and other data) ${ }^{1} ;(4)$ eliminate the fuzzy value and literature. Applying these criteria, this paper got a group of 35 empirical studies including 34 in English and 1 in Chinese 1.Among them, 19 references in the United States, this is $54 \%$ of the total number of documents, 3 in England, 2 in Netherlands, Spain, Italy, and Canada, 1 in Australia, France, Germany and China. In order to analyze the relationship between factors and collaboration proneness, all literature must be coded including: (1) the identification code of each research;(2) the literature sources;(3) publishing year;(4) research methods;(5) number of total sample. And it should comply with rules as follows: (1) each independent sample must be coded once, if there are multiple independent samples, it should be repeated; (2) literatures which use the same sample should be coded only once.

\subsection{Dimension of Variable and Analytical Model}

Based on the reviews of factors on innovation collaboration, a framework was established about key factors and their effectiveness on collaboration proneness of university, as is shown in table 1.The factors include academic ability(ACA), funding(FUN), regulation(REG),scale(SCA). The indices include ranking(RAN),N-papers(NP), industry(IND), government( GOV), regulation(REG), university(UNI), enterprise(ENT).

\begin{tabular}{cccc} 
Table 1 Relationship and Dimension of Collaboration and Variables \\
\hline Factors & Index & Explain for index & $\begin{array}{c}\text { Expected } \\
\text { relationship }\end{array}$ \\
\hline ACA & RAN & AUTM、RAE & Negative \\
& NP & overall number of publishes & Positive \\
FUN & IND & funding from industry or other & Positive \\
& & enterprises & \\
& GOV & funding from government, or & Negative \\
& & other public foundation & \\
REG & REG & support of university on & Positive \\
& & innovation collaboration & \\
& UNI & overall number of faculty and & Positive \\
& & researchers & \\
& & &
\end{tabular}

\footnotetext{
${ }^{1}$ We use correlation coefficient(r value) and Se as the main effect value, any other value must switch according to: $\mathrm{Se}=\mathrm{b} / \mathrm{t}$; $\mathrm{r}=\operatorname{sqrt}\left(\mathrm{t}^{2} /\left(\mathrm{t}^{2}+\mathrm{df}\right)\right)$
} 
The purpose of this paper is to summarize the factors that affect the proneness of UIC in innovation collaboration. For this reason, this paper uses the model of Stanley and Jarrell (1989), which conforms to the assumption of classical linear model. The formula is as follows:

$$
Y_{j}^{*}=\boldsymbol{\beta}_{0}+\sum_{k=1}^{k} \beta_{k} Z_{k j}+e_{j}, \quad k=1,2, \ldots, N
$$

The $\mathrm{Y}_{\mathrm{j}}^{*}$ represents the proneness in innovation collaboration of university and college. In the overall number of $\mathrm{N}$ papers, $\mathrm{j}$ refers to the explanatory variables in this research which reflect the difference among studies. The $e_{\mathrm{j}}$ represents the random perturbation and obeys the normal distribution. If $\beta$ proves to be significant, the variable $\mathrm{j}$ has an impact on proneness of innovation collaboration.

\section{Results}

\subsection{Heterogeneity Test}

In order to make sure whether there is discrepancy between each variable, heterogeneity test must be taken. This article uses the Cochrane Q test, and calculate the value of $\mathrm{I}^{2}$, the specific results are provided in table 2 . As is shown, there is obvious heterogeneity among factors which affect innovation cooperation proneness between university and industry $\left(\mathrm{P}<0.05, \mathrm{I}^{2}>75 \%\right)$.In this occasion, the random model will be used to correct the effects of heterogeneity, in order to make further analysis.

Table 2 Results of Heterogeneity Test ${ }^{\text {a }}$

\begin{tabular}{|c|c|c|c|c|c|c|}
\hline \multirow{2}{*}{ Factors } & \multirow{2}{*}{ Index } & \multirow{2}{*}{$\mathrm{K}^{\mathrm{b}}$} & \multirow{2}{*}{$\mathrm{N}^{\mathrm{c}}$} & \multicolumn{3}{|c|}{ Heterogeneity } \\
\hline & & & & Q & $\mathrm{I}^{2}$ & $\mathrm{P}^{\mathrm{d}}$ \\
\hline \multirow[t]{2}{*}{ ACA } & RAN & 12 & 6730 & 5296.76 & $99.8 \%$ & 0.000 \\
\hline & NP & 14 & 15611 & 4037.64 & $99.7 \%$ & 0.000 \\
\hline \multirow[t]{2}{*}{ FUN } & IND & 16 & 10886 & 8733.53 & $99.8 \%$ & 0.000 \\
\hline & GOV & 21 & 21945 & 4748.07 & $99.6 \%$ & 0.000 \\
\hline REG & REG & 15 & 12231 & 2479.59 & $97.4 \%$ & 0.010 \\
\hline \multirow[t]{2}{*}{ SCA } & UNI & 8 & 5294 & 2245.82 & $99.7 \%$ & 0.000 \\
\hline & ENT & 11 & 5368 & 8382.74 & $99.9 \%$ & 0.000 \\
\hline
\end{tabular}

Note: a. the dependent variable must be innovation cooperation proneness; $\mathrm{b} . \mathrm{K}$ refers to the number of research samples. c. N refers to the total sample size; d. Q and 12 refer to statistics value of heterogeneity test; if $\mathrm{P}<0.05$, the heterogeneity is positive.

\subsection{Factors of University on Innovation Collaboration}

Based on the result of heterogeneity test, secondly, this paper calculates the average effect size. The results of the calculations are shown in Table 3. In this paper, we get the combined effect of factors on innovation collaboration tendency by calculating weighted average $r$ value of different variables through $\mathrm{R}$ language as well as significance test. As is provided, beside university scale, the regulation, enterprise scale, ranking, N-papers, industry funding, government funding tend to be significant $(\mathrm{P}<0.05)$, and all are positive, which is consistent with traditional research. In addition to $\mathrm{N}$-weighted correlations and related statistical test, the results also provide an opportunity to compare and evaluate the effectiveness of each factor. A brief discussion for each factor follows.

Table 3 Information on Studies included in the Meta-analysis

\begin{tabular}{cccccccc}
\hline \multirow{2}{*}{ Factor } & \multirow{2}{c}{ N-weighted } & \multicolumn{2}{c}{$95 \% \mathrm{CI}$} & \multicolumn{2}{c}{ Z-Test } \\
$\mathrm{s}$ & Index & \multicolumn{2}{c}{ correlations } & & & & \\
\cline { 3 - 8 } & & $\overline{\mathrm{r}}$ & $\mathrm{p}$ & Lower & Upper & $\mathrm{z}$ & $\mathrm{p}$ \\
\hline ACA & RAN & $0.7059^{* * *}$ & 0.000 & 0.332 & 0.888 & 3.2295 & 0.000 \\
& NP & $0.4722^{* * *}$ & 0.000 & 0.186 & 0.684 & 3.0976 & 0.002 \\
FUN & IND & $0.6376^{* * *}$ & 0.000 & 0.294 & 0.835 & 3.272 & 0.001 \\
& GOV & $0.4341^{* * *}$ & 0.000 & 0.184 & 0.631 & 3.2749 & 0.001 \\
REG & REG & $0.4827^{* * *}$ & 0.000 & 0.275 & 0.647 & 4.231 & 0.000 \\
SCA & UNI & 0.0049 & 0.102 & -0.454 & 0.462 & 0.0192 & 0.9846 \\
& ENT & $0.6287^{* *}$ & 0.001 & 0.101 & 0.88 & 2.2706 & 0.001 \\
\hline
\end{tabular}

Note: $* * *(* *, *)$ indicates a significance level of $1 \%(5 \%, 10 \%)$.

Academic Ability. Ranking in this article mainly refers to AUTM (Association of University Technology Managers) in the United States and RAE University rankings in the UK. The results of RAE test can be representative of the British university academic ability. As is shown, ranking of university has a positive association with collaboration proneness with industry, which conforms to the studies of Ponomariov (2008) and Perkmanna (2012), for access to resources demand, the low level of university is more involved in industrial cooperation. But this conclusion will change in different region. For example, Giuliani \&Arza (2009) found that in Chile, the higher level of scientific research in colleges and universities, the stronger university cooperates with industry. In Italy, the result was opposite. However, in the view of the enterprise, it prefers to cooperate with a high level of university (Wei, 2013). Therefore, the difference between the ideal objects of different organizations is 
likely to be a harmful effect on the depth of cooperation. It not only needs the adjustment of government policy, but also the consultation and planning by both parties to achieve a long-term beneficial relation.

$\mathrm{N}$-papers. N-papers refer to the number of published papers of university and college faculty which stand for the overall academic ability. As is shown in Table 3, $\mathrm{N}$-papers of university have positive relationship with innovation cooperation proneness $(\overline{\mathbf{r}}=0.4722, \mathrm{p}<0.001)$. It indicated that university or college with highly published papers is more likely to cooperate with industry, which conforms to the studies of Gulbrandsen and Smeby (2005). The reason may be that faculty with abundant publishes are easily to obtain industrial funding which will promote innovation collaboration.

Funding. Funding is an important factor that affects university in collaboration proneness, including scientific research funds, laboratory equipment and public facilities, etc. The $\mathrm{N}$-weighted correlations follow (Industry funding: $\overline{\mathbf{r}} \quad=0.6376, \mathrm{p}<0.001 ;$ government funding: $\overline{\mathbf{r}} 0.4341, \mathrm{p}<0.001)$. The result is similar to some studies. Such as, D'Este (2007) found that innovation cooperation proneness will boost with the increase of income of university's scientific research. In the same way, Gulbrandsen\&Smeby (2005) investigated Norway researchers and found that those who get industry-funded show greater willingness in collaboration. Compared with industry funding, government tend to be less influencing.

Regulation. Regulation is one of the factors of innovation cooperation, which refers to atmosphere of enthusiasm in university and the degree of cooperation, such as the salary reward or further study opportunity for faculty, or whether university resources are open to partners, etc... Results of meta-analysis suggests that regulation of university has positive relationship with innovation cooperation proneness $(\overline{\mathbf{r}}=0.4827, \mathrm{p}<0.001)$, which fits the traditional conclusion. Louis et al. (1989) argued that the regulation had a profound impact on individual behavior. When university support UIC, the researchers are more likely to cooperate with other organization (Azagra - Caro et al., 2006). Adversely, the nonsupport of colleges and universities will reduce the possibility of the cooperation (Boardman, 2009).

Scale of University. The results show that the
University Scale is not significant in the role of influencing cooperative proneness ( $\overline{\mathrm{r}}=0.0049$, $\mathrm{p}=0.102>0.1,95 \% \mathrm{CI}$ contains zero), which indicates that the existing model cannot determine the correlation relationship between the two sides. Further study is needed because the impact of university scale on innovation cooperation proneness may be more complex than it can imagine.

Scale of Enterprise. Different from university, the meta-analysis suggests that Enterprise Scale has a highly positive association with innovation collaboration $(\overline{\mathrm{r}}=0.6287, \mathrm{p}<0.001)$.This indicates that the larger companies are, the higher proneness university will have. It may be due to larger enterprises have greater resources, which will generate more positive effect on cooperation, at the same time maintaining a long-term cooperation of both sides.

\subsection{Moderating Effect}

Moderator in meta-analysis refers to the overall system differences. In the management science, it includes measurement, sample characteristic, situational factors and so on. This paper selects appropriate contingency variables for factors according to the results of meta-analysis. Table 4 show the results. Subgroup analysis is one of common method in which all samples divide into several groups according to some potential factors, and then analyze within each subgroup ${ }^{[3]}$.If $95 \%$ CI does not overlap, the moderator has a huge impact on subgroup, in another word, and it is a heterogeneous source in meta-analysis. 
Table 4 Results of Differences between Mean Correlations of

\begin{tabular}{|c|c|c|c|c|c|c|c|c|c|c|}
\hline \multirow{3}{*}{$\begin{array}{l}\text { Ind } \\
\text { ex }\end{array}$} & \multicolumn{10}{|c|}{ Moderators' Subgroups } \\
\hline & \multirow{3}{*}{$\begin{array}{c}\text { Countr } \\
\mathrm{y}\end{array}$} & \multirow{3}{*}{$\mathrm{K}$} & \multirow{3}{*}{$\overline{\mathrm{r}}$} & \multicolumn{2}{|c|}{$95 \% \mathrm{CI}$} & \multirow[t]{3}{*}{ Data } & \multirow[t]{3}{*}{ K } & \multirow{3}{*}{$\overline{\mathbf{r}}$} & \multicolumn{2}{|c|}{$95 \% \mathrm{CI}$} \\
\hline & & & & \multirow{2}{*}{$\begin{array}{c}\text { Lowe } \\
\text { r }\end{array}$} & \multirow{2}{*}{$\begin{array}{c}\text { Uppe } \\
\text { r }\end{array}$} & & & & \multirow{2}{*}{$\begin{array}{c}\text { Low } \\
\text { er }\end{array}$} & \multirow{2}{*}{$\begin{array}{l}\text { Uppe } \\
\text { r }\end{array}$} \\
\hline & & & & & & & & & & \\
\hline RA & USA & 5 & 0.90 & 0.89 & 0.91 & Direct & 8 & 0.67 & 0.65 & 0.69 \\
\hline $\mathrm{N}$ & EUR & 6 & 0.43 & 0.40 & 0.46 & Indirect & 4 & 0.74 & 0.72 & 0.76 \\
\hline \multirow[t]{2}{*}{ NP } & USA & 4 & 0.37 & 0.35 & 0.39 & Direct & 12 & 0.48 & 0.47 & 0.50 \\
\hline & EUR & 10 & 0.59 & 0.58 & 0.61 & Indirect & 2 & 0.56 & 0.53 & 0.60 \\
\hline IN & USA & 8 & 0.88 & 0.88 & 0.88 & Direct & 4 & 0.72 & 0.24 & 0.92 \\
\hline $\mathrm{D}$ & EUR & 2 & 0.89 & 0.89 & 0.90 & Indirect & 6 & 0.91 & 0.33 & 0.99 \\
\hline GO & USA & 11 & 0.90 & 0.89 & 0.90 & Direct & 14 & 0.87 & 0.87 & 0.87 \\
\hline $\mathrm{V}$ & EUR & 10 & 0.51 & 0.49 & 0.52 & Indirect & 7 & 0.68 & 0.67 & 0.69 \\
\hline $\mathrm{RE}$ & USA & 6 & 0.65 & 0.64 & 0.67 & Direct & 11 & 0.48 & 0.46 & 0.50 \\
\hline G & EUR & 9 & 0.62 & 0.61 & 0.64 & Indirect & 4 & 0.83 & 0.83 & 0.84 \\
\hline UN & USA & 2 & 0.74 & 0.72 & 0.76 & Direct & 7 & 0.38 & 0.35 & 0.41 \\
\hline I & EUR & 6 & 0.13 & 0.10 & 0.16 & Indirect & 1 & 0.23 & 0.17 & 0.29 \\
\hline EN & USA & 5 & 0.90 & 0.89 & 0.91 & Direct & 8 & 0.52 & 0.50 & 0.54 \\
\hline $\mathrm{T}$ & EUR & 6 & 0.25 & 0.21 & 0.28 & Indirect & 3 & 0.85 & 0.83 & 0.86 \\
\hline
\end{tabular}

As is shown, country is one of moderators which influence fix factors: Ranking, N-papers, Industry funding, Government funding, University scale, Enterprise scale. As to country, 95\% CI does not overlap which illustrates the national policy and other related political factors greatly affect the university's strategy in the innovation cooperation. The cooperation degree depends on the support of national policy. In addition, data access also affects six factors including Ranking, N-papers, Government funding, Regulation, University scale, Enterprise scale, which means the way of data acquisition influenced the literature conclusion.

\section{Limitations and final conclusions}

Based on the meta-analysis, this paper studied the related literature at home and abroad and made a review on the organizational level for the key factors of cooperative proneness of university. The research shows that, first, on the organizational level, this paper determines the factors that influence the university to participate in innovation cooperation, including university rankings, enterprise scale, government funding, industry funding, which have a positive impact on cooperation proneness. However, in analysis of university scale, the effect was not significant, for there may be a more complex relationship, which need further inspection. Second, the effectiveness of external factors (enterprise scale, government funding, industry funding), than internal factors (university scale, regulation, ranking) on university are more profound. What's more, influence of government funding is greater than the industry. Third, the country, data acquisition are the moderators that adjust cooperation proneness of the relationship between various factors, which explain the differences among different researches. Through the quantitative study, this paper found that there is a lack of related literature of innovation cooperation from the view of a university. The empirical analysis was so scarce that become a big disadvantage of meta-analysis, which led to the inaccurate results. In order to make the research better and more comprehensive, the future research needs more related literature, and analyzes heterogeneity among factors of university innovation cooperation at home and abroad.

\section{Acknowledgements}

The paper was supported by National Natural Science Foundation of China (71473086, 71233003), General research for philosophy and social sciences Project of Ministry of Education of China (12JZD042) , Natural Science Foundation of Guangdong Province (S2013010011823). The authors also want to thank anonymous referees for comments affecting the final text.

\section{References}

[1] Lee. The Sustainability of University-Industry Research Colla boration: An Empirical Assessment[J]. Journal of Technology Transfer.2000,25:111-133

[2] Giuliani et al.. Who are the researchers that are collaboratin $\mathrm{g}$ with industry? An analysis of the wine sectors in Chile, S outh Africa and Italy [J]. Research Policy.2010:1-14

[3] Senker J. Changing organization of public-sector research in Europe - implications for benchmarking human resources in RTD [J]. Science and Public Policy.2001,28(4):277-284;

[4] Azagra-Caro et al. Faculty support for the objectives of univ ersity-industry relations versus degree of $R \& D$ cooperation:T he importance of regional absorptive1 - capacity [J]. Research Policy, 2006,35: 37-55

[5] Bekkers.R. Freitas.B. Analyzing knowledge transfer channels between universities and industry: To what degree do sectors also matter? [J]. Research Policy.2008,37:1837-1853

[6] Bercovitz.J. Feldman.M. The mechanisms of collaboration in inventive teams: Composition, social networks, and geograp hy [J]. Research Policy.2011,40:81-93 
[7] Boardman.P. Ponomariov.L. University researchers working w ith private companies[J]. Technovation. 2009, 29: 142-153

[8] Bozeman.B. Gaughan.M. Impacts of grants and contracts on academic researchers' interactions with industry[J]. Research Policy.2007,36:694-707

[9] D'Este .Patel. University-industry linkages in the UK: What are the factors underlying the variety of interactions with in dustry? [J]. Research Policy.2007,36: 1295-1313

[10] Gibbons.M., Limoges.C., Nowotony, H., Schwartzman, S., Scott, P. Trow, M. The new production of knowledg e: The Dynamics of Science and Research in Contemporary Societies [M]. London: Sage, 1994.

[11] Gulbrandsen.M. Smeby.J. Industry funding and university pro fessors'researchperformance [J]. Research Policy.2005,34:932-9 50

[12] Landry et al. Determinants of knowledge transfer: evidence $f$ rom Canadian university researchers in natural sciences and engineering[J]. Technol Transfer.2007,32:561-592 